\title{
A "geração podcasting" e os novos usos do rádio na sociedade do espetáculo e do entretenimento*
}

\section{RESUMO}

Buscou-se repensar a importância da espetacularização e da alta visibilidade como fatores que permitiriam aos atores sociais "negociar" sentidos e significados na sociedade contemporânea. Considera-se as apropriações das novas tecnologias um estudo de caso que permite avaliar as possibilidades de construção de linhas de fuga na sociedade atual, marcada por uma forte presença dos media e do entretenimento. Analisou-se o novo nicho de produção e consumo midiático viabilizado pela convergência tecnológica - especificamente o podcasting, modalidade de rádio sob demanda -, repensando a atuação dos usuários no estabelecimento de formas inovadoras de sociabilidade e mediação socioculturais.

\section{PALAVRAS-CHAVE}

espetáculo

rádio

podcasting

\section{ABSTRACT}

This paper on rethinkis the role of spectacularization, and high-visibility. Both factors seems to allow social actors to "negotiate" senses, significations in nowadays society. The appropriation of new technologies is considered as a study case, in order to evaluate possible escape lines in a society characterized by widely spread media and entertainment. A new niche of media consumption and production, introduced by the convergence of technologies, especially podcasting, that is, on-demand radio, is also analyzed. Moreover, the stablishment of users' innovative forms of sociability and sociocultural mediations are discussed.

\section{KEY WORDS}

spectacle

radio

podcasting

\section{Micael Herschmann}

Professor e coordenador do Programa de Pós-Graduação em Comunicação da ECO/UFRJ/RJ/BR

micaelmh@globo.com

\section{Marcelo Kischinhevsky}

Professor do Departamento de Comunicação da PUC-Rio/RJ/BR marcelokisch@gmail.com
O entretenimento é hegemônico na sociedade atual, constituindo-se em uma referência cultural e uma força econômica fundamental (TRIGO, 2003; DYER, 2002). Ao mesmo tempo, quando observamos os sentidos relacionados à palavra constatamos uma forte conotação negativa. Sua etimologia é de origem latina e vem de inter (entre) e tenere (ter). A maioria dos sentidos associados à palavra tangencia a idéia de "iludir" ou "enganar". Gabler, provocativamente, lembra que a estética do entretenimento - já no século XIX - vinha se tornando mais célebre que outras expressões artísticas e que os detratores do entretenimento têm realmente "razão". É tudo o que dizem: "divertido fácil, sensacional, irracional, previsível e subversivo (...) é por isso que tantas pessoas o adoram" (GABLER, 1999, p. 27).

Este autor, ironicamente, ressalta que o fato de que boa parte da intelectualidade e setores conservadores ou aristocráticos da sociedade nunca prezou muito a diversão e a fruição, explica o enorme preconceito que geralmente cerca a noção de entretenimento. Além disso, ele destaca que estes atores sociais, invariavelmente, tiveram uma enorme desconfiança em relação à "sensibilidade" ou "gosto" popular que, quase sempre, é o público dessa produção massiva e espetacularizada.

Entretanto, o que significa viver em uma sociedade do entretenimento, intensamente espetacularizada? Ainda que seja possível constatar um uso expressivo e difuso do conceito de espetáculo - tanto por parte da sociedade quanto do universo acadêmico - continuamos, lamentavelmente, carecendo de análises e investigações mais sis-temáticas sobre o fenômeno da espetacularização e de suas implicações sobre a dinâmica do mundo contemporâneo ${ }^{1}$. Alguns teóricos argumentam que a sociedade contemporânea realizaria um investimento "excessivo" na imagem, no espetáculo. Atribuem a este investimento constante, à intensa movimentação e ao consumo dos atores em torno das performances, um sinal invariavelmente negativo: tomam este fato como um traço hedo-nista da sociedade atual ou um indício do esvaziamento da esfera pública, do interesse dos indivíduo-s pelo COLETIVO (NOVAES, 2005; SUBIRATIS, 1989; BAUDRILLARD, 1991).

Poder-se-ia afirmar que esta espetacularização está diretamente relacionada à hipertrofia dos meios de comunicação em grande parte do globo, em especial na segunda metade do século XX. A midiatização da sociedade contemporânea opera sempre como pano de fundo das críticas sobre a centralidade do espetáculo em nossos dias. No presente artigo busca-se analisar um novo nicho de produção e consumo midiático viabilizado pela convergência tecnológica (CASTELLS, 1999) - as novas modalidades de radiodifusão, notadamente o podcasting 
-, repensando o papel dos atores sociais no estabelecimento de formas inovadoras de mediação socioculturais (MARTÍN-BARBERO, 1997). Partimos da hipótese de que a postura política de toda uma geração de podcasters, surgida nos últimos três anos, não só fornece subsídios para uma revisão das críticas que, em geral, são feitas à sociedade contemporânea espetacularizada, mas também se apresenta como um objeto de estudo relevante para os pesquisadores da área de comunicação avaliarem as novas interações sociais que vêm emergindo com a popularização das tecnologias digitais.

\section{A intensa espetacularização da sociedade contemporânea}

Ainda que se possa atestar uma saturação da arena política tradicional e um investimento considerável na fruição, isso não necessariamente revela o desinteresse da sociedade contemporânea pelo político. O espetáculo contemporâneo parece indicar a emergência de uma nova arena política - midiática - e a importância da esfera da cultura ou dos fatores culturais como vetores capazes de mobilizar efetivamente os atores sociais. A hipótese que norteia a argumentação desenvolvida aqui é de que a espetacularização e a alta visibilidade, construídas no ambiente midiático, são estratégicas para que discursos e ações (políticas) alcancem êxito hoje (HERSCHMANN, 2005). Além disso, o espetáculo é um traço característico da sociedade contemporânea, mas não necessariamente reflete aspectos negativos a serem extirpados do social, vindo a se constituir numa ameaça à "razão" - ainda que a crise dos "projetos coletivos" e das noções iluministas seja mais do que evidente. Ou seja, o espetáculo deve sempre ser analisado criticamente, mas pode ser agenciado por diferentes atores sociais e organizações, podendo estar a serviço da normatização social ou da construção de uma perspectiva ou de ações críticas que coloquem em pauta, por exemplo, reivindicações de diferentes grupos sociais.

Mais do que com a simples teatralização, hoje, convivemos com a espetacularização que, a sua maneira, "reencanta" o drama contemporâneo e o mundo. Não é à toa que autores como Gabler argumentam que a vida social - constituinte do self-, em certo sentido, virou um "filme" (1999). Esse fato, segundo o autor, traz conseqüências para o debate sobre o impacto da espetacularização na sociedade contemporânea. Se, por um lado, o "filme-vida" (a vida como entretenimento) representa um "escapismo", por outro, as narrativas performá-ticas dos atores sociais são exibidas na nova arena política (midiática), abastecendo-nos de sentidos e significados e orientando-nos no cotidiano ${ }^{2}$.

É preciso reconhecer que o espetáculo, como advertem Hardt e Negri, pode estar hoje a serviço do "biopoder globalizado" ${ }^{\prime 3}$, promovendo experiências não só de fruição e escapismo, mas também reiterando e legitimando idéias, ações, valores e códigos sociais. Entretanto, esses autores ressaltam que o espetáculo pode também ser agenciado pelas minorias e usado como estratégia para se alcançar mobilização social e realizar "resistências", agregando diferentes públicos em torno de um conjunto de questões lançadas na cena midiática.

Não se está, portanto, ignorando a função normatiza-dora dos meios de comunicação sobre o social. É importante identificar as possibilidades de fazer emergir o "outro" no campo midiático. Possibilidades que devem ser tomadas como meta pelas ações políticas e culturais. Nesse sentido, esse campo midiático pode vir a se constituir numa arena de luta importante de construção de uma realidade social mais plural e democrática. Entretanto, para que isso aconteça é necessário que os atores sociais, em particular os grupos minoritários, utilizem linguagens e "estratégias" adequadas que serão empregadas nas "máquinas de subjetivação" fundamentais hoje para a (re)construção de sentidos e significados $^{4}$. Está mais do que óbvio que, no mundo atual, o que não tem intensa visibilidade ou não se espetaculariza dificilmente vai adquirir relevância social ou política.

Não se trata aqui de ratificar as interpretações mais sombrias, que sugerem, entre outras coisas, que a sociedade atual caminharia na direção da atomização social. Mesmo reconhecendo os inúmeros riscos que a forte presença do espetáculo pode representar para a sociedade contemporânea, busca-se nes-te artigo enfatizar e analisar o potencial dos agenciamentos do espetáculo e das novas tecnologias de comunicação realizados pelos indivíduos e os grupos sociais, isto é, a capacidade de construírem - a partir dessas apropriações - linhas de fuga, novos referenciais e significados às suas vidas.

\section{A geração podcasting}

Atores e lideranças de grupos sociais e/ou comunitários têm reiterado em vários trabalhos e relatos seu empenho em utilizar o enorme potencial de mobilização social de produtos midiáticos como redes peer-to-peer (P2P, serviços de compartilhamento de arquivos digitais), podcasts, webtevês, entre outros. Entre estas experiências, chama a atenção o crescimento acelerado do podcasting. Não há números precisos sobre o número destas estações, mas uma rápida pesquisa nos principais diretórios da web indica que já estão na casa das centenas de milhares ${ }^{5}$.

O podcasting desperta especial interesse devido ao fato de que o meio rádio - que já foi veículo privilegiado em projetos de construção de identidades nacionais e esvaziou-se ao longo das últimas décadas - vive um momento de redefinição, diante da revolução trazida pela convergência tecnológica. Diversos sistemas de rádio digital encontram-se em fase de testes ou implantação, alterando dramaticamente a forma de recepção radiofônica, com desdobramentos profundos na indústria da cultura e do entretenimento.

Tentaremos analisar de forma breve as novas modalidades de rádio via internet para detalhar os impasses e as possibilidades que oferecem hoje. A partir daí, vamos procurar discutir questões relativas ao consumo de produtos midiáticos, à circulação destes conteúdos e ao 
processo de comunicação em si, no qual os novos receptores convertem-se, cada vez mais, também em emissores, graças a condições inéditas de produção.

Até muito recentemente, o tema havia despertado a atenção de poucos autores (CASTRO, 2005, PRIMO, 2005, e LEMOS, 2005). O podcasting, modalidade de radiodifusão sob demanda, virou febre na internet entre 2004 e 2005. Seu surgimento está vinculado à emergência da chamada web 2.0, conceito que abrange o desenvolvimento de relações mais horizontais entre os diversos atores sociais conectados à rede mundial de computadores (ANTOUN e PECINI, 2007).

O internauta se cadastra num endereço eletrônico, instala programas agregadores e de leitura de arquivos digitais de áudio (que podem ser baixados gratuitamente via internet), busca podcasts de sua preferência e, a partir daí, recebe os programas (também chamados "episódios") em seu computador. No podcasting, diferentemente da radiodifusão convencional, a recepção é assincrônica, cada indivíduo decide quando e onde vai ouvir o conteúdo assinado. O podcast é descarregado no computador e, a partir daí, pode ser consumido imediatamente ou copiado para um tocador multimídia (telefone celular, iPod, MP3 players), sendo fruído de uma única vez ou de forma fragmentada.

Embora a tecnologia estivesse disponível desde 2001, esse meio só parece ter se popularizado com o surgimento de grandes diretórios de rádio via internet, nos quais é possível abrigar emissoras gratuitamente. Estes portais organizam e classificam os conteúdos de áudio na rede, proporcionando maior visibilidade tanto aos podcasters ${ }^{6}$ quanto aos webcasters ${ }^{7}$.

A novidade reforça a onda de downloads de música na internet, iniciada com o surgimento de sites de compartilhamento de arquivos musicais, como Napster, Freenet e KaZaA, a partir de 1999. Essas redes P2P já vinham abalando a indústria fonográfica, que qualificou de pirataria a troca de músicas protegidas por direitos autorais e procurou criminalizar a prática, mesmo com fins não-comerciais (SANTINI, 2006). A diferença é que, agora, com o podcasting, não apenas a posição das grandes gravadoras de discos fica em xeque, mas também a própria mediação exercida pelas redes convencionais de rádio. O fenômeno aprofunda o processo de reestruturação vivido pelas multinacionais da música na última década (KISCHINHEVSKY e HERSCHMANN, 2006) e redefine sua tradicionalmente simbiótica relação com a indústria radiofônica.

O podcasting franqueia ao consumidor a opção de pôr "no ar" programações radiofônicas que gostaria de ouvir, mas que não encontra no dial. Inicialmente, os podcasts eram, na maioria, seqüências de músicas da predileção do internauta. Mas, rapidamente, os programas/ episódios passaram a se sofisticar, mesclando locuções, efeitos sonoros, trilha. Na maioria dos casos, os conteúdos permanecem presos aos formatos de programas do rádio analógico. Contudo, vêm ganhando força outras formas de expressão que transcendem a gramática das emissoras comerciais, como a veiculação de análises, palestras, debates. Podcasts foram lançados também por empresas, com fins de comunicação corporativa, devido às vantagens oferecidas pelo armazenamento de dados para divulgação ${ }^{8}$.

O nome podcasting remete diretamente ao mais popular aparelho tocador de MP3, o iPod, da Apple, sinal de distinção social num mundo de acesso profundamente desigual às novas tecnologias da informação e da comunicação ${ }^{9}$. Levantamento da consultoria americana Bridge Data mostra que $88 \%$ dos internautas que assinam podcasts carregam seus tocadores de MP3 com os arquivos recebidos. Contudo, relatório da Universidade de Washington, referente à experiência educacional conduzida no período letivo de 2005/2006, aponta que a mobilidade não era importante para $87 \%$ dos alunos que fizeram download de arquivos das aulas ${ }^{10}$.

Ou seja, o podcasting apresenta múltiplos usos e não pode ser relacionado exclusivamente à explosão nas vendas de tocadores multimídia, embora tenha participação relevante na expansão da oferta de aparatos portáteis. A nova modalidade de rádio sob demanda parece distante da lógica do broadcasting do rádio analógico, mas pode guardar parentesco tanto com as micromídias quanto com as mídias de nicho (PRIMO, op. cit.). Ou mesmo constituir uma espécie de "mídia negocial", ao ensinar "o usuário a consumir conteúdo distribuído de forma legalmente sancionada pela indústria cultural" como no caso da loja virtual da Apple, a iTunes Music Store (CASTRO, op. cit.)

Em casa ou na rua, a audiência dos podcasts cresce em ritmo acelerado, pelo menos de acordo com os parcos dados estatísticos disponíveis. Em seis meses do ano de 2006, nos EUA, a expansão da base de internautas que baixam programas/episódios foi da ordem de $70 \%$, segundo pesquisa da Pew Internet \& American Life Project: $12 \%$ do total, contra $7 \%$ de levantamento anterior ${ }^{11}$.

Certamente, um fator de sedução é a ausência de regras rígidas nos podcasts. Não há padrões de locução ou restrições em termos de linguagem e temas abordados. A principal hierarquização se dá por meio dos diretórios, que, muitas vezes, classificam as emissoras a partir de rótulos preexistentes, com ancoragem nas rádios convencionais.

No caso do portal Live365, as web radios e os podcasts divididos em 23 gêneros, como "rock", "folk", " alternative", "hip-hop/rap", "classical", "country", "latin" e "electronic/dance", ganham destaque na ferramenta de busca. Mesmo assim, o leque de opções é bem mais abrangente: pode-se navegar por outros 263 gêneros, atribuídos pelos próprios webcasters e podcasters, em ordem alfabética. Entre eles, debates políticos, contracultura, serviços religiosos, assuntos governamentais, humor etc. ${ }^{12} \mathrm{E}$, embora a segmentação, em linhas gerais, reflita a adotada pelas emissoras FM, grande parte dos podcasts se alimenta de músicas licenciadas para livre 
reprodução - em vez do copyright, ou direito autoral, estes trabalhos são protegidos por copyleft, referência ao projeto Creative Commons. A licença do tipo CC permite que outros indivíduos copiem, distribuam, exibam, executem e até criem obras derivadas, com as ressalvas de atribuição de crédito ao autor e de uso sem fins comerciais - cláusulas de que o artista também pode abrir mão, se assim desejar, abrindo caminho para criações coletivas via internet (KISCHINHEVSKY, 2006).

Com o barateamento dos equipamentos de informáti$\mathrm{ca}$, criar condições materiais para ser ouvido deixa de constituir questão primordial: há uma apropriação dos meios de produção por parte dos usuários. Lemos vê uma "liberação do pólo de emissão" (op. cit.). Os receptores-consumidores - muitos deles amparados pela ideologia punk do faça-você-mesmo - tornaram-se também emissores e, atirando suas garrafas ao mar, conseguiram criar fenômenos midiáticos, de repercussão variável.

O cenário atual não guarda ligação direta com o surgimento do movimento das rádios livres e comunitárias, a partir dos anos de 1970 e 1980, na Europa e na América Latina (GUATTARI, 1981; GUATTARI e ROLNIK, 2005; CALLEJA E SÓILIS, 2005; KISCHINHEVSKY, 2007a). É certo que o podcasting atende aos anseios de organizações não-governamentais, movimentos sociais e ativistas de minorias étnicas, religiosas, sexuais etc., fornecendo condições materiais para veiculação de conteúdos políticos e culturais a custos muito mais baixos ${ }^{13}$. Mas, de nenhuma forma, o novo meio fica circunscrito a este universo de militância, contemplando igualmente projetos de caráter nacionalista, separatistas, fundamentalistas, tribos urbanas, grupos de afinidade transnacional, pesquisadores, amantes de artes plásticas, entre outros atores sociais.

Com milhões de potenciais podcasters, o debate se desloca para as estratégias de visibilidade em tempos de comunicação pulverizada, via rede mundial de computadores. Os novos usos possibilitados pelo rádio sob demanda engendram novas sociabilidades, mas resta saber como outras formas de mediação sociocultural se relacionarão com o fenômeno. No momento, os podcasts parecem constituir importante ferramenta de democratização do acesso à informação e ao discurso, embora não ofereçam garantias de que os conteúdos veiculados de fato atingirão os públicos visados. Poder-se-ia, a esta altura, perguntar: até que ponto o rádio convencional e as demais mídias vão se realimentar da atual revolução?

\section{Considerações finais}

A reconfiguração das indústrias do rádio e da música causa impacto direto sobre o campo da cultura. Embora os podcasts e as web radios ainda constituam uma fração do mercado, representam a face mais visível de um processo de transformação na mídia sonora, redesenhando os circuitos de produção, veiculação e consumo da música popular massiva e da informação radiofônica.
Garimpar música desconhecida através do podcasting é uma experiência sensorial nova, que pode ser performatizada e, assim, ganhar valor na sociedade contemporânea, marcada pela alta visibilidade e pelo espetáculo (PINE e GILMORE, 2001; HERSCHMANN, 2007). Isto é, com o avanço da tecnologia de compressão de arquivos digitais e a crise da indústria fonográfica, o podcasting começa a inaugurar novas formas de sociabilidade e a constituir toda uma rede de identificações culturais, valorizadas e prestigiadas pelos usuários.

Perdem força as mediações tradicionais realizadas pela indústria da música e do entretenimento, organizada em torno de paradas de sucessos, grandes vendagens de discos e veiculação de conteúdos de forma sincrônica; ganham terreno a pluralidade nas representações artísticas, as redes transnacionais de identificações culturais, a interação social mediada, as transmissões radiofônicas assincrônicas e as novas formas de audição. Esse fenômeno parece estar apenas começando.

Este artigo buscou apenas mapear algumas das questões relacionadas à nova realidade do rádio e da mídia sonora na sociedade do espetáculo e do entretenimento. Estudos adicionais serão empreendidos para que possamos compreender melhor sua extensão mFAmEcos

\section{NOTAS}

* Texto apresentado no GT- Mídia e Entretenimento, durante o $16^{\circ}$ Encontro Anual da (Compós), na Universidade Tuiuti do Paraná (UTP), em 2007. Agradecemos ao $\mathrm{CNPq}$ pelo apoio à investigação que serviu de base para a realização deste artigo e aos colegas de GT pelas diversas observações pertinentes, aqui incorporadas.

1 A obra seminal de Guy Debord (1997) é freqüentemente citada, mas pouco conhecida. Para mais detalhes, ver FREIRE FILHO, 2005.

2 A mídia emergiria como principal espaço de produção e de experimentação da memória e de construção de sentidos. É especialmente no interior dos espaços midiáticos que se travam as disputas simbólicas que engendram referencia-lidades, ou seja, é nos circuitos midiáticos de produção e consumo que se constroem interpre-tações do passado e do presente que disputam hegemonia. Sobre a importância da mídia como um "lugar de memória" e de construção de sentidos, ver HERSCHMANN E PEREIRA (2005).

3 HARDT e NEGRI (2001) retomam o conceito de $b i$ opoder de FoucAult (2004.) à luz das observa-ções realizadas por DELEUZE e GUATTARI (1998), ressaltando que, se nas sociedades disciplinares o biopoder era parcial (portanto, mais passível de resistência), nas sociedades atuais, de controle (e globalizadas), o quadro é mais complexo, pois todo o corpo social é absorvido nas máquinas de poder. As 
grandes corporações transnacionais não só produzem mercadorias, mas também - através das máquinas de subjetivação (compostas por novas tec-nologias de informação sofisticadas e pelos meios de comunicação) - co-produziriam senti-dos e desejos.

4 Felix Guattari ressaltou ao longo de sua obra a importância de se apropriar dos veículos de comunicação visando à promoção de um pensa-mento "nômade", rlix argo de sua obra GUATTARI e ROLNIK, 2005; DELEUZE e GUATTARI, 1998, realização do que denomi-nava "revolução molecular", capaz de produzir e fazer emergir novas subjetividades minoritá-rias (GUATTARI, 1981; GUATTARI e ROLNIK, 2005; DELEUZE e GUATTARI, 1998).

5 Só a fornecedora de serviços de distribuição eletrônica de mídia FeedBurner - controlada pela Google Inc. - atende 240,7 mil podcasts e

videocasts. Cf. o endereço, http:// www.feedburner.com/fb/a/podcasts (Última consulta: 16 de junho de 2008.)

6 Nome dado ao internauta que publica regularmente, em endereços eletrônicos, conteúdos para download em que o áudio é o suporte preponderante.

7 Aqueles que veiculam programação radiofônica na internet, por meio de web radios. Nesta modalidade de radiodifusão, geralmente a transmissão ocorre de modo sincrônico, como no dial. Apenas programas específicos ou conteúdos especiais são oferecidos sob demanda e, muitas vezes, não é possível baixálos, mas apenas ouvi-los online.

8 Meios de comunicação tradicionais têm aderido à onda, lançando podcasts que reforçam o consumo e a circulação de seus produtos, como íntegras do áudio de entrevistas. Raros, no entanto, são os que operam como diretórios, abrigando estações cujos conteúdos não tenham sua chancela. Uma exceção notável na grande imprensa brasileira é a página Link, do portal do jornal O Estado de S. Paulo, na qual é ossível hospedar podcasts gratuitamente.

9 Levantamento da Computer Industry Almanac apontou a existência de 903,9 milhões de computadores pessoais em todo o mundo, ao final de 2005. Deste total, 230,4 milhões estavam nos EUA, ou três para cada quatro americanos. O Brasil aparecia em $11^{\circ}$ lugar no ranking, com 22,4 milhões - um para cada sete. Ver Folha Online, 30 de maio de 2006, “Mundo tem 900 milhões de PCs; Brasil soma 22 milhões”.

10 Ao final de setembro daquele ano, podcasts eram usados como ferramentas auxiliares de ensino em cerca de 20 cursos só no campus de Seattle. Os downloads de arquivos superavam a marca de 45 mil, e a reitoria planejava expandir a oferta. Ver "University podcasts", David Aldrich, artigo postado no site Podcasting News, em 23 de novembro de 2006.

11 Artigo "Podcast audience up by $70 \%$ in 6 months", postado no site Podcasting News, em 22 de outubro de 2006.

12 Extraídos de: http://www.live365.com/listen/ browse.live (acesso: 12 jan de 2007). O Live365

- que se apresenta como líder mundial no segmento - informa ter "milhares" de podcasts e web radios, representando internautas de mais de 150 países, com cerca de quatro milhões de ouvintes por mês. Entre os gêneros listados, havia pelo menos três dedicados ao Brasil: "Brazilian", "bossa nova" e "tropicália".

13 Pôr no ar uma rádio comunitária exige o trabalho de um grande número de pessoas, além de gastos com equipamentos de transmissão, de alcance muitas vezes limitado a um raio de poucos quilômetros. Já no podcasting, qualquer computador com acesso à internet, instalado nos pontos mais remotos do globo, pode receber a programação veiculada, às vezes por um único indivíduo.

\section{REFERÊNCIAS}

ANTOUN, Henrique, PECINI, André Custódio (2007). A web e a parceria: Projetos colaborativos e o problema da mediação na Internet. Anais do $16^{\circ}$ Encontro da Compós, realizado na UTP.

ANTOUN, Henrique (2002). Comunidades virtuais, ativismo e combate pela informação In: Lugar Comum. Rio : CNPq/NePCOM-ECO-UFRJ, n. 15-16.

BAUDRILLARD, Jean (1991). Simulacro e simulações. Lisboa: Relógio D'Água.

CALLEJA, Aleida e SOLÍS, Beatriz (2005). Con permiso. La radio comunitaria en México. Cidade do México: Fundación Friedrich Ebert.

CASTELLS, Manuel (1999). A sociedade em rede. Rio: Paz e Terra.

CASTRO, Gisela G. S. (2005). Podcasting e consumo cultural. E-Compós. Brasília: Associação Nacional dos Programas de Pós-Graduação em Comunicação, edição 5.

CEBRIÁN HERREROS, Mariano (2001). La radio en la convergencia multimedia. Barcelona: Gedisa.

DEBORD, Guy (1997). A sociedade do espetáculo. RJ: 
Contraponto.

DELEUZE, Gilles e GUATTARI, Felix (1998). Mil platôs. São Paulo: Ed. 34, v. 1-5.

DYER, Richard (2002). Only Entertainment. N Y: Routledge.

FOUCAULT, Michel (2004). Microfisica do poder. Rio: Graal.

FREIRE FILHO, João (2005). Usos (e abusos) do conceito de espetáculo na teoria social e na crítica cultural. In: FREIRE FILHO, João e HERSCHMANN, Micael (orgs). Comunicação, cultura $\mathcal{E}$ consumo. A (des) construção do espetáculo. RJ: E-Papers, pp. 13-44.

GABLER, Neal (1999). Vida, o filme. Como o entretenimento conquistou a realidade. São Paulo: Cia. das Letras.

GUATTARI, Felix (1981). Revolução molecular: pulsações politicas do desejo. São Paulo: Brasiliense.

GUATTARI, Felix e ROLNIK, Suely (2005). Micro-politica: cartografias do desejo. Petrópolis: Vozes.

HARDT, Michael e NEGRI, Antonio (2001). Império. RJ: Record.

HERSCHMANN, Micael (2007). Alguns apontamentos sobre a reestruturação da indústria da música in: FREIRE FILHO, João e HERSCHMANN, Micael (orgs). Novos Rumos da Cultura da Mídia. RJ: Mauad X, pp. 161-188.

HERSCHMANN, Micael (2005). Espetacularização e alta visibilidade: a politização do hip-hop no Brasil Contemporâneo. In: FREIRE FILHO, João e HERSCHMANN, Micael (orgs). Comunicação, cultura $\mathcal{E}$ consumo. A (des)construção do espetáculo. RJ: E-Papers, pp. 153-168.

HERSCHMANN, Micael e PEREIRA, Carlos Alberto M. (orgs.) (2005). Mídia, memória E celebridades. RJ: EPapers.

KISCHINHEVSKY, Marcelo e HERSCHMANN, Micael . A indústria da música brasileira hoje - Riscos e oportunidades. In: FREIRE FILHO, João e JANOTTI JUNIOR, Jeder (orgs.). Comunicação E música popular massiva. Salvador: EDUFBA, pp. 87-110.

KISCHINHEVSKY, Marcelo (2007a). O rádio sem onda Convergência digital e novos desafios na radiodifusão. RJ: E-Papers. (2007b). Os portais e a segmentação no rádio via Internet. In: FREIRE FILHO, João e HERSCHMANN, Micael (orgs.). Novos rumos da cultura da mídia: indústrias, produtos, audiências. RJ: Mauad X, pp. 189-211.

KISCHINHEVSKY, Marcelo (2006). Manguebit e novas estratégias de difusão diante da reestruturação da indústria fonográfica. Ciberlegenda. Niterói: PPGCOM/UFF, n. 16.

LEMOS, André (2005). Podcast: emissão sonora, futuro do rádio e cibercultura. $404 n O t F 0 u n d$, v. 1, n. 46, Salvador.

LÉVY, Pierre (1999). Cibercultura. São Paulo: Ed. 34.

MARTÍN-BARBERO, Jesús (1997). Dos meios às mediações. Rio: Ed. UFRJ.

NOVAES, Adauto (2005). Muito além do espetáculo. São Paulo: Ed. SENAC.

PEREIRA, Carlos Alberto M.; HERSCHMANN, Micael (2002). Comunicação e novas estratégias organizacionais na Era da Informação e do Conhecimento. In: Comunicação E Sociedade. São Bernardo: Umesp, n. 32 , pp. 27-42.

PINE, B. Joseph e GILMORE, James. O espetáculo dos negócios. RJ: Campus, 2001.

PRIMO, Alex Fernando Teixeira (2005). Para além da emissão sonora: As interações no podcasting. Intexto, n. 13, Porto Alegre.

REIN, Irving; KOTLER, Philip (1999). Marketing de alta visibilidade. São Paulo: Makron Books.

SANTINI, Rose Marie (2006). Admirável chip novo: A música na era da internet. RJ: E-Papers.

SUBIRATIS, Eduardo (1989). A cultura do espetáculo. São Paulo: Nobel.

TRIGO, Luiz Gonzaga G. (2003). Entretenimento. São Paulo: Ed.SENAC.

TURKLE, Sherry (1997). A vida no ecrã. A identidade na era da Internet. Lisboa: Relógio D’Água. 